\title{
ELICITING MULTIMEDIA FEATURES FOR MOBILE MUSEUM CATALOGUES
}

\author{
Renata Rizzo-Silveira \\ Universidade Federal do Rio Grande do Sul \\ r.rizzodesign@gmail.com \\ Gabriela Trindade Perry \\ Universidade Federal do Rio Grande do Sul \\ gabriela.perry@ufrgs.br \\ Joyson Pacheco \\ Universidade Federal do Rio Grande do Sul \\ joyson@mecanica.ufrgs.br
}

\begin{abstract}
The mobile user of the museum catalogue is becoming more attuned to what technology can offer - simply rendering a publication in a mobile format is no longer sufficient. User expectations now encompass multimedia content and an enhanced user experience. There are, however, many ways in which multimedia can be deployed, and a direction to this design choice is needed to maintain focus on the role of museum catalogues. In response, we report how the Delphi method was used to guide the selection of the best features. The results showed that paradoxically, users desire catalogues with multimedia features, but retain a preference for examples with passive levels of interaction.
\end{abstract}

Key words: Design, mobile, interactivity, multimedia, museum catalogues.

\section{INTRODUCTION}

The spread of smart mobile devices continues, but the shift of printed museum catalogues into digital formats has lagged behind the technological advances. With a growing number of institutions looking to take advantage of the mobile revolution, the convenience of merely adapting a publication to a flattened digital format is flooding the market with monotonous digital editions. This poses a challenge to the institution - how to preserve their identity and character in a contemporary multi-resource technology while maximising the platform and price advantages of mobile. Our research investigates which multimedia features apply best to museum catalogues.

Museum catalogues can be considered a category of publishing on their own distinguished from books, magazines and newspapers - where image is the main feature. One of the ways to add value to digital publications is to exploit multimedia (i.e. audio, animation and video), interactivity and customization.

This paper shows how we used the Delphi method to help selecting multimedia features with a focus on museum catalogues, so they can leverage the emerging 
technologies and go beyond the printed versions, without losing touch with the artist, the exhibition and the institution.

\section{MUSEUM CATALOGUES}

The activity of museum documentation emerged due to the development of modern museums [...] when mere access lists have become insufficient and more detailed information is now necessary to manage the collections and to gather objects for special exhibitions. (Almeida, 2006)

Catalogues are books published by museums, art galleries and artists, with the aim of documenting the material of a certain collection or cultural event (i.e. exhibition, show, performance). Often the photos published are the only permanent record of this type of ephemeral event. Catalogues contains images of works and may also bring additional texts, essays, list of works and biographies. They show artworks in a way that makes them appealing and accessible to readers (Corrigan, 2011) acting as a source of reference for discussions, research, reference and historical record for customers spanning collectors, trustees, employees, sponsoring organizations, guest artists, students and visitors.

Regarding design needs, museum catalogues are very peculiar publishing pieces. They are publications where the compositional elements like grid, layout, typography and the book itself are secondary and should support the presented artworks (Corrigan, 2011), as it focuses the reproduction of drawings, prints and paintings, of sculptures and photographs. One should see these images as large as possible, at a size at which all the details of the original can be discerned (Hochuli \& Kinross, 1996).

In distinction from other literature categories, where text and image cohabit pages in harmony, a publication of this kind should highlight images. Pages are designed to be "viewed". A book with visual predominance creates narrative through the position and size of images (Fawcett-Tang, 2007); text is usually restricted to foreword, captions. When necessary, biographies and list of works should be added, as they have documental value, but they should be as invisible as possible to accentuate images that are the main feature.

Images communicate ideas that are rooted in human experience of the world. In a publication images can be photographs, illustrations (in the sense of drawing and painting) or a hybrid - manipulated photographs or combination of drawn pictures (Samara, 2011). These images are codes that reflect events in situations, processes in scenes. Not that they can make events eternal or replace events for scenes - they are considered mediations between man and world. Images are representations of the world (Flusser, 2002).

In digital devices, catalogues continue with the same intent of the print versions but introduce a technological bias, images that were once the main feature of the publication must share space with a range of options as important as they are. The user now has images in form of video, games, $360^{\circ}$ photography, live-capture, or virtual reality, all accompanied with sound and interactivity. It's what we call a living catalogue. 


\section{THE DELPHI METHOD}

The Delphi method originated in a series of studies conducted by the RAND Corporation in the 1950s. The goal was to develop a technique to obtain the most reliable consensus of a group of experts (Dalkey \& Helmer, 1963).

Linstone \& Turoff (1975) emphasize the commonality between different versions of the method: it structures a group communication process so that it is effective in allowing the group to act as a whole, handling a complex problem. To accomplish this, it provides: feedback on individual contributions; information and knowledge; analysis of group judgments or opinions; opportunity for individuals to revise their views and a degree of anonymity for individual responses.

All Delphi variances are structured around a series of sequential questionnaires that are combined with summaries of comments from respondents. Through this interactive process, the Delphi method allows a group of geographically dispersed experts to consistently progress a complex task, where a single correct answer is not necessarily available. The Delphi method was originally developed for the U.S. Air Force with the aim of estimating the effects of an atomic bomb attack, but the method's predictive capabilities are now used in a variety of contexts. Today, there is no typical Delphi methodology and it has been suggested that the term 'Delphi Approach' best characterizes divergent interpretations and methodological studies (Mead \& Mosely, 2001).

The main advantage of the approach is that it avoids direct confrontation of experts. Dalkey \& Helmer (1963) observe that the controlled interaction appears more conducive to independent thinking on the part of the experts and to assisted them in the gradual construction of a distinct opinion. On the other hand, direct confrontation, as in focus groups, often leads to hasty formulation of concepts, an inclination to close your mind to new ideas, a tendency to defend a position once taken, or alternatively, a predisposition to be influenced by the opinions of persuasive members of the group.

Despite being a powerful research tool, the Delphi method is still strongly debated in the scientific community. Wheelwright \& Makridakis (1985) criticize some aspects, including differing results for different experts, and difficulty in assessing the degree of expertise of the participants. On the other hand Schmidt (1997) notes two points acting strongly in favour of the Delphi method, the first is the preference of the particular opinion instead of the confrontation face to face, and the second claims the superiority of the opinion of the group over the individual.

Another interesting point we should mention is anonymity, which undoubtedly reduces the impact of dominant individuals in a group process (Dalkey, 1972), levelling any inter and intra-institutional hierarchies.

The Delphi method originally required as a result that the participants' opinions converge to a common point. With the development of Delphi and depending on the type of information the consensus need not to happen, and here another one of its variations, the Policy Delphi. This seeks to generate conflicting opinions with three basic objectives: to ensure that all possible options were offered, to estimate the impact and the consequences of any particular option and observe the acceptability of any particular option (Turoff, 1975).

We have chosen the Delphi method because it is adaptable in its design and does not require experts to meet physically, which could be impractical for international experts. This theme is narrow, and number of experts with knowledge on 
the required fields is restrict, the Delphi panel size is not ambitious, this makes it easier to survey answers, allowing the collection of deeper information.

\section{APPLIED METHODOLOGY}

The methodology we will present in this paper starts with one of the most neglected aspect of the Delphi method - choosing appropriate experts (Okoli \& Pawlowski, 2004).

\subsection{Selecting Experts}

Aligning to the orientations of Dalbecq et al. (1975) this paper uses a method with the following steps to recognize and classify the experts.

\subsubsection{Step 1 -Create a background/skills form}

The idea is to think about the knowledge needed to answer the questions before having names to fill in the form. Experts were chosen through their backgrounds basically align under the umbrella of the art and museum industry. Because of the nature of our problem, it required people with knowledge and practice with museum catalogues, exhibition content, collections, graphic and web design, artworks, communications, and an up to date knowledge of multimedia content, mobile apps and features.

Backgrounds were grouped in three main categories:

- $\quad$ Content producers (curators, writers and teachers)

- Designers

- $\quad$ Artists

Content producers have a deep understanding of the collections and exhibition frequency, usually aware of visiting numbers and survey assessments they are able to individualize features that are important to the public. Designers and artists have the knowledge of reaching specific public through catalogue content, art showcasing and displaying. Chosen experts had also a high level of familiarity with mobile devices.

The balance of each group is shown in the graphic bellow. The content producers group $(n=15)$ is larger than the designers $(n=8)$ and the artists $(n=10)$ groups, due to the diversity of backgrounds of experts located here.

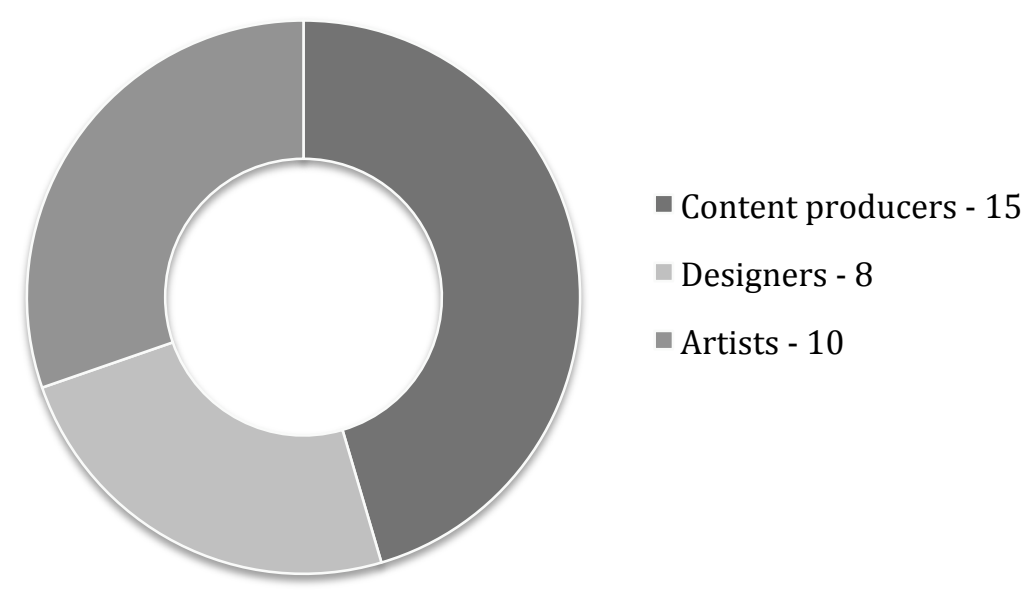

Figure 1: Expert background chart, designed by the author based on research numbers 


\subsubsection{Step 2 - Filling the form with expert names}

After defining the classes of experts, the forms were filled with names under the groups: governmental organizations, private organizations, practitioners, and academics. Using classes and headings a very large number of experts are expected to populate the list and at this stage we need as many names as possible. Names are then added from personal networks trying to fit in each category/group. Government organizations: museum, tourism boards and universities; private organizations: banks, press, museums, industry, societies and universities; practitioners: designers, artists, collectors, journalists, writers, promoters and academics: tutors, researchers, writers.

\subsubsection{Step 3 -Contact nomination of additional experts}

Since the previous step was the nomination of people from personal networks we assumed sufficient knowledge of listed experts. These people were then contacted; the Delphi and the significance of their collaboration were explained. Then they were asked to nominate at least two other experts to broaden the list.

\subsubsection{Step 4 - Engaging experts}

Three groups were created, and with a target to achieve a minimum of 10 people per group (Dalbecq et al., 1975), each expert was contacted. And project details, objectives were carefully explained. A timeline was created; they were informed about the amount of time they were supposed to spend with the participation. In the beginning four rounds with a total of seven questions were planned. Time estimated of 10 to 15 minutes estimated to complete each question. Time estimated was based on a rehearsal test realized by a team member, and communicated to participants.

Our goal was to engage people through a transparent explanation of the study and the method, to make them feel an important part of the process, and to provide an extended view of the subject so they could also broaden their own knowledge.

\subsection{Information collection}

We have used the conventional method, via email, to overcome geographical diversity - we had researchers and experts from three different continents; it would have been impossible to gather all groups together at the same time, as suggested in the "real time" method.

\subsubsection{First round - Brainstorming}

The first three questions listed below were sent by email to identified experts in direct response to their agreement to participate in this research. We called it "brainstorming" phase because experts were asked to write their thoughts freely. For the first round the questions were:

1-List at least six factors that affect the growth of exhibition catalogues for mobile devices;

2-List at least six multimedia features that can add value to mobile catalogues;

3-Provide a brief explanation for your choice of each factor listed in the first two questions.

The first question introduces the theme, and opened the paths to the second question that was the core of this round, and of the study itself. The answers of second question have built up the list that we worked through. The third question had 
qualitative answers and was an aid for further classification, as well as a source for future groups to be named.

\subsubsection{Second round - Confirmation}

Answers for the second question of the previous round were compiled into a list, doubled words/meanings were edited. This list was sent back to experts with the following request:

4-Please Check if your answers were interpreted correctly and allocated to the appropriate category;

\subsubsection{Third round - Ranking features}

The list was then edited and completed according to the answers. We sent back the list to the participants, asking:

5- Rate (1-5) each item according to relevance to mobile museum catalogues - 1 being the most important 5 being the less important.

6- After that write a brief explanation on your choices.

In this round each expert produced a commented list. The average was calculated for each item, and the list was then sorted from the most important to the less important items (from 1 to 5 points).

We planned a fourth round, where we would have sent to experts the ranked list for a hierarchy confirmation. The question was:

7-Please take into consideration the ranking average and consider re-rating any item you consider misplaced.

As we had faced a high mortality (a high number of experts leaving the project), this fourth question round was not sent, and list was considered confirmed.

At the end of the process we had a hierarchized list of multimedia features that are significant to mobile versions of museum catalogues. The intense collaborative work on the theme and the direct relationship of experts' knowledge of the subject guaranteed the features on the list are truly important and the relative values between them were respected. Based in this list we were able to shorten the path of designers when choosing best features to include in mobile catalogues.

\section{RESULTS}

Delphi proved to be a resourceful method for this research. It helped researchers to achieve the objective in a transparent and descriptive process. Although, because of its multiple round nature, Delphi posed a challenge to this research: how to engage experts to be part of the process until the end.

We were aware that there would be a tendency of withdrawal in the process before reaching the end, due to misunderstanding of the amount of time experts should dedicate answering the questions, or due to simple lack of patience. Trying to minimize this situation, steps 3 and 4 were carefully planned and methodology was explained. Yet, some experts required extra effort to feel engaged, until they were convinced of the importance of their participation on the research. Even though, only $31 \%(n=10)$ of total participants reached the final round.

What surprised us was that $27 \%(n=9)$ of invited experts directly denied participation: some claimed they didn't had time, other said they didn't feel confortable with the study's theme. $18 \%(n=6)$ gave up after the first round, and $6 \%$ $(n=2)$ left the process after participating the first two rounds. 
Despite this, when used with creativity, thoughtfulness and care, Delphi remains an extremely valuable instrument to several activities; especially those that intend to predict future actions.

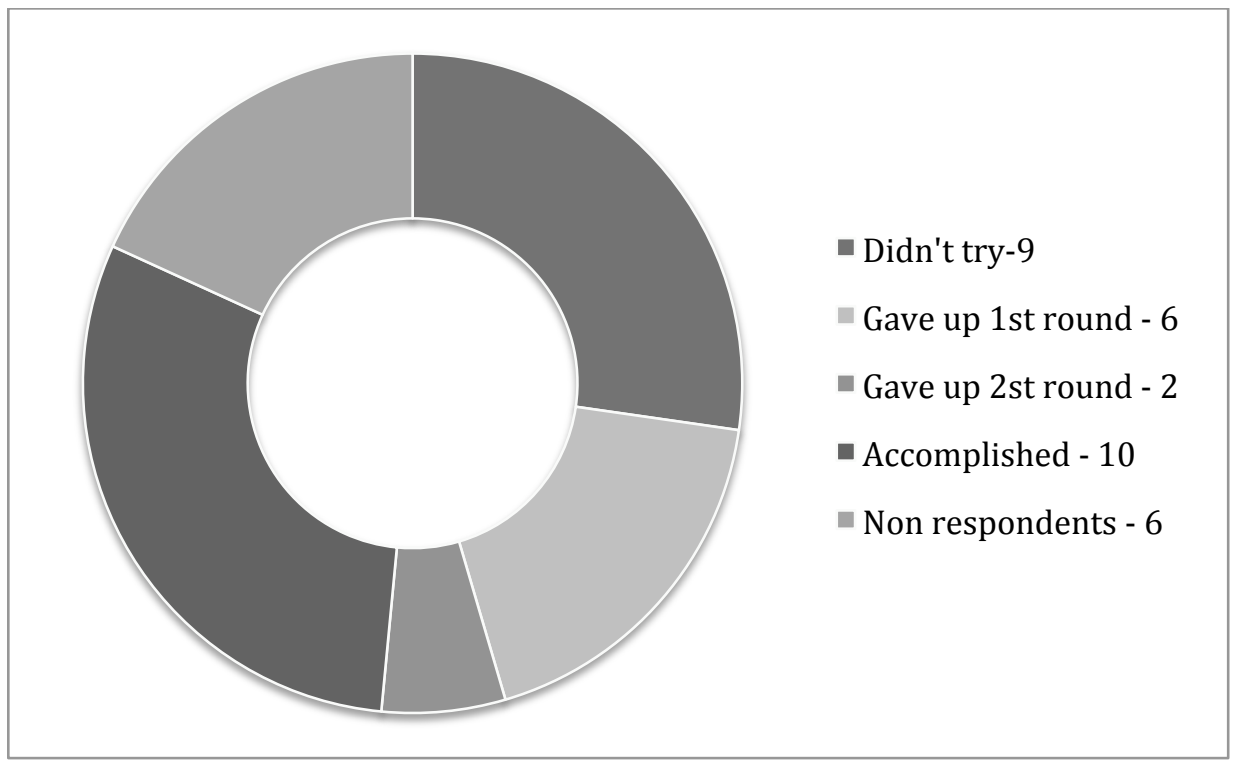

Figure 2: Expert participation percentage designed by the author based on research numbers

\subsection{Accepting the challenge}

We have some evidence that the instructions we gave about the knowledge required of participants sometimes were not clear, leading to a non-acceptance since the beginning. For example one expert commented, "I really don't really have an idea of what you are referring to as 'Mobile museum catalogues'", this expert actually owns two interactive websites with services of professional photography and video production, studio creating stills and moving images for any screen, for print, and the web, had personal exhibitions of photography's in museums and art galleries. Another one commented, "I apologize. But I do not even know how to begin to answer and also explain each item. I think I cannot help you!" this expert had designed dozens of museum, galleries and artist catalogues and also holds a personal website with a virtual shop to his designs with a downloadable app to mobile devices. Other experts claimed time efforts would be a problem and stating: "I'd love to participate, but I can't ... Can I talk to you informally in a cafe ... but I can not join four rounds plus the return by email ... even if this issue is also of interest to me" and "Usually I participate in research but our son was born this week, and I can not commit to you, there are four rounds and I have no way to respond on time".

\subsection{The outcome}

The list presented in Table 1 shows the features suggested by subjects of this research, hierarchically organized according to their classification, and presents partial results of the data collection. The answers of this sample have curious features, as at the same time we are looking at the future of museums and seeing technology, interaction, use of five senses on the learning process, the results described on the 
ranked list (regarding multimedia features) for mobile museum catalogues indicate that the preferred features are the ones that doesn't require much interaction (the passive ones). For example: Virtual Visits, Interactive Table of Contents and Link to Artist's Page were highly ranked, while the more interactive ones like Games, Chats and Curiosities were left far behind.

We observed that the feature's rank figures decreased in an inverse proportion to the increasing of content density, becoming less important as the content becomes heavier. For example: the video showing step-by-step exhibition mounting has not been seen by subjects as one of the most important features (with a 4.20 score) but, sometimes, the content in this feature is of real importance to the understanding of some artist's working path or the engineering behind the scenes of a sciences museum. Perceived interactivity would affect other related cognitive theories in addition to ease of use and usefulness (Cousaris \& Sung, 2012), because interactivity reflects in time consuming, the deeper and focused the content, the more time is needed to be elapsed to the interaction.

Table 1: Hierarchized multimedia features list designed by the author based on research numbers

\begin{tabular}{lc} 
Multimedia features & Average \\
\hline Virtual visit & 1.40 \\
Interactive content table & 1.40 \\
Artist's website & 1.40 \\
Spoken info & 1.60 \\
Artist' biography & 1.60 \\
Audio/Video for special needs & 1.80 \\
Language choice & 1.80 \\
Working objects video & 2.00 \\
Content choice tool & 2.00 \\
Zoom & 2.00 \\
360 ${ }^{\circ}$ pictures & 2.00 \\
Extended details about objects & 2.00 \\
Events agenda & 2.20 \\
Spoken details about objects & 2.40 \\
Soundtrack & 2.60 \\
Hipertext & 2.60 \\
Interview with artists & 2.80 \\
International Sign language & 2.80 \\
Social network & 2.80
\end{tabular}

$\begin{array}{ll}\text { Animations } & 3.00 \\ \text { Extra content related to the show } & 3.00 \\ \text { Similar works } & 3.00 \\ \text { Ideal route choice } & 3.20 \\ \text { Search tool } & 3.20 \\ \text { Supporting bibliography } & 3.20 \\ \text { Comments } & 3.40 \\ \text { Ombdusman } & 3.40 \\ \text { Extra content on techniques } & 3.40 \\ \text { Additional texts } & 3.60 \\ \text { Working instalations video } & 3.80 \\ \text { Virtual camera } & 3.80 \\ \text { Link to related areas } & 3.80 \\ \text { Virtual environment exclusive pieces } & 3.80 \\ \text { Link to general media } & 4.00 \\ \text { Making off } & 4.20 \\ \text { Step by step mounting the show } & 4.20 \\ \text { Games } & 4.40 \\ \text { Chats } & 4.40 \\ \text { Curiosities } & 4.40\end{array}$

On the perception of interactivity, Yang (2008) conducted a qualitative research to find which kind of features contribute this perception in the mobile web setting, and identified five levels that would characterize mobile interactivity: Two-way Communication, Active Control, Synchronicity, Richness of Content and Connectedness. Based on Yang's (2008) research we have crossed the information obtained from the ranked list, framed the features into Yang's (2008) proposed categories. The list shown in Table 2 is the result of this crosscheck. 
Table 2: Features reorganized according to Yang (2008) categories designed by the author based on research numbers

\begin{tabular}{lcc} 
Multimedia features & Average & Yang(2008) \\
\hline Events agenda & 2.20 & 1 \\
Comments & 3.40 & 1 \\
Ombdusman & 3.40 & 1 \\
Games & 4.40 & 1 \\
Chats & 4.40 & 1 \\
Intractive content table & 1.40 & 2 \\
Virtual visit & 1.40 & 2 \\
Audio/Video for special needs & 1.80 & 2 \\
Language choice & 1.80 & 2 \\
Zoom & 2.00 & 2 \\
Ideal route choice & 3.20 & 2 \\
Search tool & 3.20 & 2 \\
Soundtrack & 2.60 & 3 \\
Hipertext & 2.60 & 3 \\
International Sign language & 2.80 & 3 \\
Virtual camera & 3.80 & 3 \\
Artist' page & 1.40 & 4 \\
Spoken info & 1.60 & 5 \\
Artist' biography & 1.60 & 5 \\
Working objects video & 2.00 & 4 \\
Content choice tool & 2.00 & 4 \\
360 ${ }^{\circ}$ pictures & 2.00 & 4 \\
Extended details about objects & 2.00 & 4 \\
Spoken details about objects & 2.40 & 4 \\
Interview with artists & 2.80 & 4 \\
Animations & 3.00 & 4 \\
Extra content related to the show & 3.00 & 4 \\
Similar works & 3.00 & 4 \\
Supporting bibliography & 3.20 & 4 \\
Extra content on techniques & 3.40 & 4 \\
Additional texts & 3.60 & 4 \\
Working instalations video & 3.80 & 4 \\
Making off & 4.20 & 4 \\
Step by step object/show & 4.20 & 4 \\
Curiosities & 2.40 & 4 \\
Social network & & 4 \\
\hline & into general media & 4 \\
\hline
\end{tabular}

Aiming to endorse previous comments, features were framed into Yang's (2008) categories, and an average grade was calculated to each level. It resulted that the Active Control category was considered of higher importance with an average of 2.11 (in a 1 to 5 scale, 1 being the most important, 5 being the less important) this refers to the user's to have control over all of the activities occurring on mobile websites, is associated with the ease of information use and the reduced efforts to complete the task (Cyr et.al., 2009; Gao et.al., 2010; Yang, 2008), Richness of Content followed in a technical draw with Synchronicity with 2.82 and 2.95 respectively - the category Richness of Content was expected to contain a higher number of features due to the focus of this research. Two-way Communication and Connectedness are situated last also in a technical draw with 3.56 and 3.6. 
Table 3: Rated Yang(2008) categories, designed by the author based on research numbers

\begin{tabular}{lc} 
Yang (2008) & New Average \\
\hline 2. Active control & 2.11 \\
4. Richeness of content & 2.82 \\
3. Synchronicity & 2.95 \\
1. Two way communication & 3.56 \\
5. Connectedness & 3.6 \\
\hline
\end{tabular}

\section{CONCLUSIONS AND DISCUSSION}

This study proposes a hierarchized list of multimedia features with a focus on museum catalogues. Delphi method was carefully used and paradoxically the results point to the direction that the most important features for mobile museum catalogues are the ones with less interaction.

In a first list sorting, using just simple average of participants ratings, the features that top the list as the most important for the mobile museum catalogues were: Virtual Visit, Interactive Table of Contents, Artists' Page, Spoken Info. These were considered passive features for example: the Virtual Visit feature means the user could experience museum spaces without leaving home; in the interactive table of contents feature user could jump directly to the contents of interest; in the Artists' Page feature they could access or store information on artists' background and the Spoken Info feature means that there could be information reading efforts - even if this feature was firstly quoted as an aid for the visually impaired. That's the paradoxical positioning we unveiled in this research, in one side the endless quest for novelty and on the other side the lack of time or desire to interact.

In a second list sorting the model was then framed into Yang's (2008) categorization of multimedia features: Two-way Communication, Active Control, Synchronicity, Richness of Content and Connectedness, and a new average was calculated. These categories can contribute to enlighten designer's work when selecting the optimal multimedia features to enhance mobile museum catalogues and other mobile publications. In this second framing personalization features (i.e., the Active Control category) arose as the most important group of features for the mobile museum catalogues. This category groups the features: Interactive Table of Contents, Virtual Visit, Audio/Video for Special Needs, Language Choice, Photo Zoom, Ideal Route Choice and Search Tool. This result corroborates the first framing and depicts the necessity for users to retain control.

Simplicity is what is expected of any usage relationship. Complexity is what is expected of any situation in return to use. Knowing the balance between the use and return is an art form of electronic dialogue (Xavier, 2010).

\section{LIMITATIONS AND FUTURE RESEARCH}

Limitations are part of all research, and this point to future paths for future studies. In this research we suffered from a high mortality of respondents. Even though expert choice followed a rigorous criterion, from the total number of professionals invited to participate in this research (33), only $31 \%(n=10)$ accomplished the assignment until the end - therefore it may not be enough to generalize the results. But, if this represents a limitation for the statistical significance of the results, 
the background of respondents reinforce the accuracy in the results. The first hierarchic list of features was generated through an open question in the Delphi's first round - it was a 39 feature list. Perhaps if the respondent number was different, we could have come to other features. However, as the objective was to propose a list of multimedia features with a focus on museum catalogues, we consider it was achieved. Lastly, we used five levels, which characterizes mobile interactivity adapted from the study of Yang (2008). As stated by Coursaris \& Sung (2012) Yang did not classify which features are explicitly associated with each level. Here there is space for further quest to achieve correspondence between the features and the categories.

This research investigated the construction of a hierarchized list of multimedia features for mobile museum catalogues, a growing interest theme. Some unpredicted results arose, the expected best-ranked features were to be the high interactive ones but differently the figures point that features with low interactivity are preferred. This is a fast developing technology so constant watching for new features is suggested.

\section{REFERENCES}

ALMEIDA, M. C. B. A informação em Museus de Arte: De unidades isoladas a sistema integrado. Musas Magazine, Rio de Janeiro, n.2, P.140- 154, 2006

CORRIGAN, J. A produção de um livro independente indie publishing: Um guia para autores, artistas e designers. Edited by Lupton, E. Translated by Rosa, M. L. São Paulo: Edições Rossari, 2011

COURSARIS, C. K.; SUNG, J. Antecedents and consequentes of a mobile website's interactivity. In: new media \& society, n.14(7), P.1128-1146, 2012

CYR et.al. Perceived interactivity leading to e-loyalty: Development of a model for cognitive -affective user responses. In: International Journal of Human Computer Studies, n. 67 P. 850-869, 2009

DELBECQ et. al. Group techniques for program planning: A guide to nominal group and Delphi processes. Scott, Foresmanand Company, Glen-View,Illinois, 1975

DALKEY, N.; HELMER O. An experimental application of the Delphi method to the use of experts. Management Science, n.9 (3), P. 458-467, 1963

DALKEY, N. Studies in the quality of life. Lexington, MA, Lexington Books, 1972

FAWCETT-TANG, R. O livro e o designer I: Embalagem, navegação, estrutura e especificação. Introduction and interviews by Roberts, C. translation by Mariz, A. São Paulo: Rosari, 2007

FLUSSER, V., O mundo codificado: por uma filosofia do design e da comunicação. Organized by CARDOSO, R. Translated by Abi-Sâmara, R. São Paulo: Cosac Nafy, 2007

FLUSSER, V. Filosofia da caixa preta: ensaios para uma futura filosofia da fotografia. Rio de Janeiro: Sinergia Relume Dumará, 2009.

GAO et.al. Measuring perceived interactivity of mobile advertisements. In: Behavior and Information Technology, n. 29(1) P.91-109, 2010

HOCHULI, J.; KINROSS, R. Designing books: practice and theory. London: Hyphen Press, 1996 
LINSTONE, H.A.; TUROFF M., The Delphi method: Techniques and applications. London: Addison-Wesley, 1975

MEAD, D. M.; MOSELY, L. G. The use of Delphi as a research approach. In: Nurse Researcher, n.8, P. 4-37, 2001

OKOLI C.; PAWLOWSKI S.D. The Delphi method as a research tool: an example, design considerations and applications. Information \& Management, n.42, P.15-29. 2004

PACHLER, N. et. al. Mobile Learning: structures, agency, practices. New York: Springer, 2010

SAMARA, T., Guia de design editorial: manual prático para o design de publicações. Translated by Bandarra, M; technical revision by Farias, P. L. Porto Alegre: Bookman, 2011

SCHMIDT, R.C. Managing Delphi surveys using nonparametric statistical techniques. Decision Sciences, n.28 (3), P.763-774. Department of Information Systems and Decision Sciences at Louisiana State, 1997

TUROFF, M. The Policy Delphi. In: The Delphi Method: Techniques and applications. London: Addison-Wesley, 1975.

XAVIER, G. A Condição Eletrolúdica: Cultura visual nos jogos eletrônicos. Teresópolis: Novas Ideias, 2010

WHEELWRIGHT, S.; MAKRIDAKIS, S. Forecasting methods for management. $4^{\text {th }}$ ed. New York: John Wiley, 1985

YANG, S. Role of perceived interactivity in intended loyalty for mobile cell-phone. 2008. Thesis (doctoral) - Purdue University, West Lafayette, IN. 